Olgu Sunumu/Case Report

\title{
Konstrüktif ring sendromu için Z plasti: Olgu Sunumu
}

\author{
$\mathrm{Z}$ plasty for constrictive ring syndrome: Case report
}

Ahmet Demir*, Fatih Söylemez, Ayhan Sönmez, M. Kemal Keleş, İ. Oğuzhan Aydoğdu

Ondokuz Mayıs Universitesi, Tip Fakültesi Plastik Rekonstrüktif ve Estetik Cerrahi Anabilim Dall

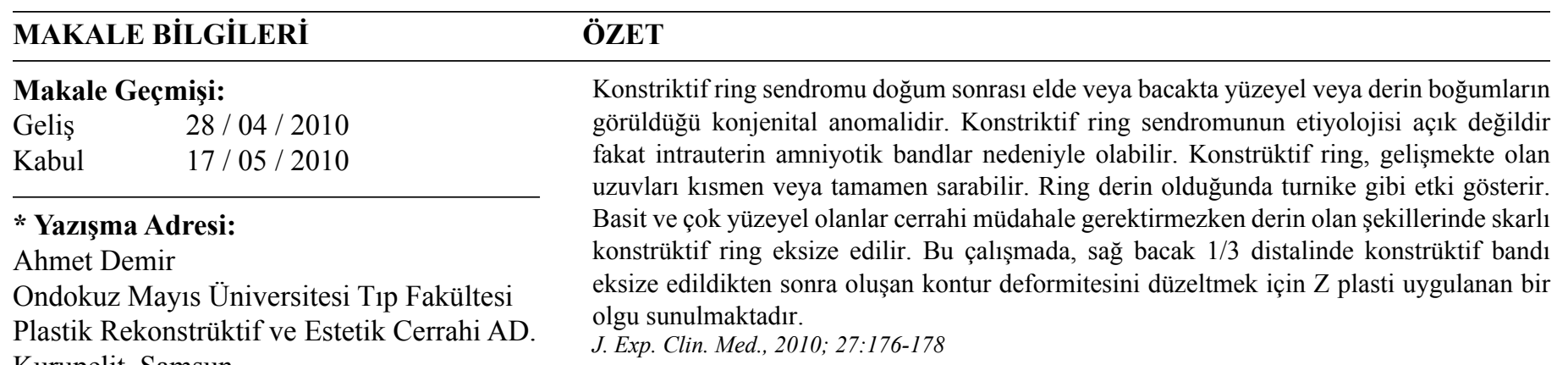

Kurupelit, Samsun

e-posta: arbdemir@omu.edu.tr

\section{Anahtar Kelimeler:}

Konstrüktif Ring Sendromu

Konstrüktif Bant Sendromu

Z Plasti

Amniyotik bant

Skar

Cerrahi

Key Words :

Constructive Ring Syndrome

\begin{abstract}
Constrictive ring syndrome is a congenital anomaly characterized by superficial or deep circumferential constrictions along the extremities. Its etiology is obscure, but intrauterine amniotic bands have been incriminated. Constructive rings can partially or totally wind around the limbs. If deep enough, they can totally obliterate the extremity. While simple and superficial constrictions do not require surgery, deep scatrized constrictive rings need to be excised. In this study, a case in which $\mathrm{Z}$ plasty has been applied to correct a contour deformity following removal a constrictive ring on the distal third of a right leg has been presented.

J. Exp. Clin. Med., 2010; 27:176-178
\end{abstract}

Constrictive Band Syndrome

Z Plasty

Amniotic band

Scar

Surgery

(C) 2010 OMÜ Tüm Hakları Saklıdır.

\section{Giriş}

Konstriktif ring sendromu daha çok elde ve bacakta yüzeyel veya derin boğumların görüldüğü konjenital anomalidir. Sendromunun sinonimleri; konjenital annuler oluk, konstrüktif bant sendromu, intrauterin veya fetal amputasyon, annuler defekttir. Etiyolojisi açık değildir fakat intrauterin amniyotik bandların ekstremiteyi sarması nedeniyle olabilir. Sporadiktir, aile öyküsü yoktur (Api ve ark., 1993). İnsidansı yaklaşık 1/15000' dir.

Derin olan konstrüktif ring; ultrasonografi ile intrauterin belirlenebilir. Konstrüktif ring, gelişmekte olan kol, el, el parmağı, ayak bileği, ayak parmağı veya diğer vücut kısımları etrafını kısmen veya tamamen sarabilir (Coady ve ark., 1998). Ring, yüzeyel veya periostun içine kadar uzana- cak şekilde derin olabilir (Bourne ve ark., 1987). Ring derin olduğunda bir turnike gibi etki gösterir ve deri altındaki yumuşak dokunun depresyonuna neden olur. Ring normal cilt krizlerine benzer ancak kemiğe kadar uzanabilir (Bourne ve ark., 1987). Bandların sebep olduğu boğumlardaki derinlik ve distalinde kalan ödem her olguya göre değişir. Derin olan konstrüktif ring; ultrasonografi ile intrauterin belirlenebilir (Filly ve ark., 1991). Konstriktif banda sekonder olarak akrosindaktili veya bandın distalinde parmakların lateral füzyonu görülebilir.

Konjenital band konstriksiyonu sendromunun 4 tipi vardır (Petterson);

Tip-I: Ciltte oyuk şeklinde basit konstriktif bant.

Tip-II: Konstriktif bant distalinde lenfödem ol- 
sun/ olmasin deformite vardır.

Tip-III: Konstriktif bant ile birlikte distal kısımların füzyonu vardır (akrosindaktili).

Tip -IV: İntrauterin otoamputasyonlar

Ortadaki uzun parmakta (3. parmak) diğer kısa parmaklara göre daha sık görülür.

Basit ve çok yüzeyel olanlar cerrahi müdahale gerektirmezken derin olan şekillerinde skarlı konstrüktif ring eksize edilir (Di Meo ve ark., 1987). Klasik olarak bandın çevresinin yarısından azının tek seferde serbestlenmesi distalde iskemi riskini azaltır (Walter ve ark., 1998). Akrosindaktilide eğer mümkünse yaşamın birinci yılında her bir parmak ayrı ayrı serbestlenmelidir (Guy ve ark., 1994). Derin olan, dolaşımı etkilemiş ve ağır fonksiyonel etkisi olan bazı konstrüktif ring sendromlu hastalarda amputasyon gerekebilir (Miur ve ark., 1985).

$\mathrm{Bu}$ çalışmada sağ bacağında ve el parmaklarında konstrüktif bantları olan hastaya, sağ bacağındaki konstrüktif bandı eksize edildikten sonra oluşan kontur deformitesini düzeltmek için Z-plasti uygulaması yapılmıştır.

\section{Olgu Sunumu}

İki aylık kız çocuğu, her iki bacağında ve sol el parmaklarında boğum şeklinde halkalar ve şekil bozukluğu nedeni ile polikliniğimize ailesi tarafindan getirildi. Hastanın sağ bacağında tibia $1 / 3$ distal bölgesinde sirküler olarak yerleşmiş, bacak çevresi $14 \mathrm{~cm}$ iken bant çevresi $7 \mathrm{~cm}$ olacak şekilde derin bir kontrüktür bant halkası bulunmaktaydı. Sağ ayakta inversiyon mevcut olup bacak sola göre kısaydı. Hastanın bant distalinde dolaşım sorunu yoktu, hafif bir ödem hali mevcuttu. Sol elinde 2,3,4 parmaklar kısa ve deforme görünümde ve 3. ve 4. parmaklar arasında köprü şeklindeki bant mevcuttu (Şek. 1). Hastanın sol ayak bileğinde de operasyon gerekmeyen basit bir bant halkası bulunmaktayd.
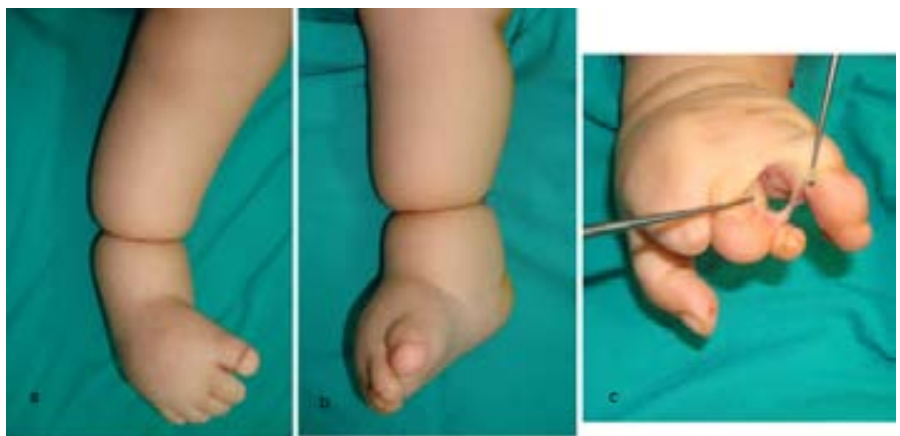

Şek. 1: Sağ bacaktaki sirküler bandın ameliyat öncesi; (a) önden, (b) iç yan görünümü, (c) sol eldeki deformasyon ve parmaklar arasındaki bant.

Hasta 6 aylık olduğunda kontraktür bandın açılmas1 ve z-plastiler ile kontürün düzeltilmesi planlandı. Genel anestezi altında ve kan dolaşımına zarar vermemek için mikroskop ile çalışılarak bant dokusu sirküler olarak çıkarıldı. Eksizyon sonrası oluşan defektte kontür deformitesini önlemek için medyal ve laterale z-plastiler uygulandı. (Şek. 2,3). Ayrıca hastanın sol elde 3-4 parmaklar arasındaki köprü şeklindeki bant eksize edildi. Hastanın takiplerinde ayak öde-

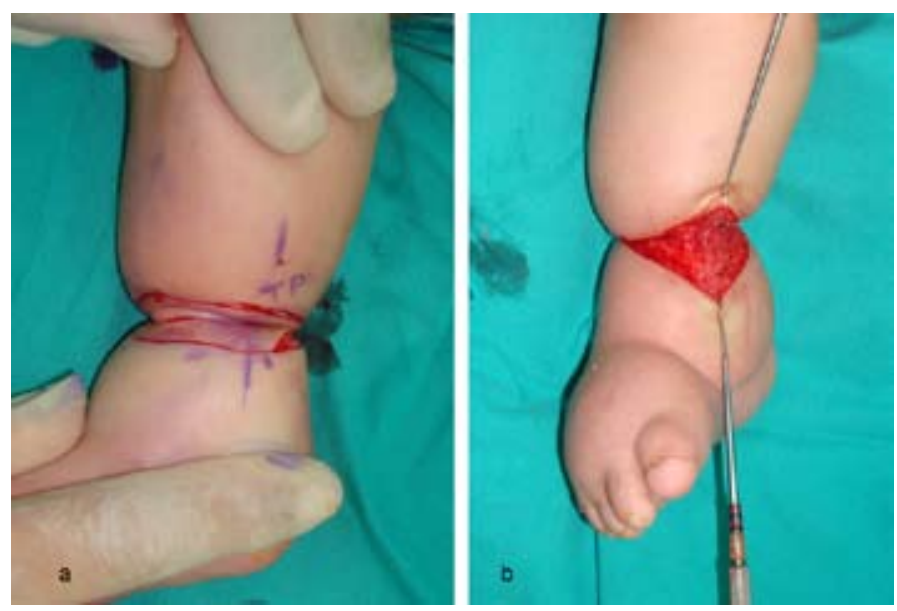

Şek. 2: Sağ bacaktaki sirküler bandın ameliyat anındaki; (a) insizyon sınırı, (b) eksizyon sonras1,

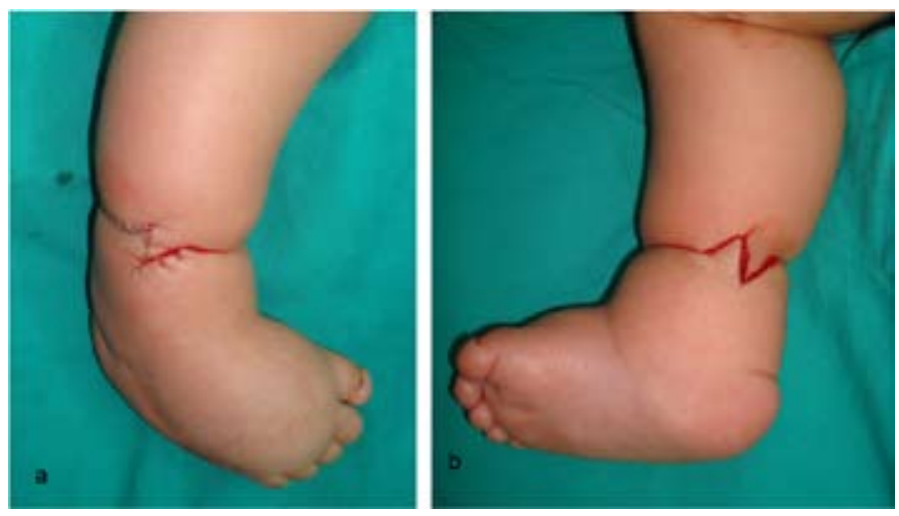

Şek. 3: Yara dudaklarına uygulanan $Z$ plastiler;(a) dış yan, (b) iç yan görünümleri.
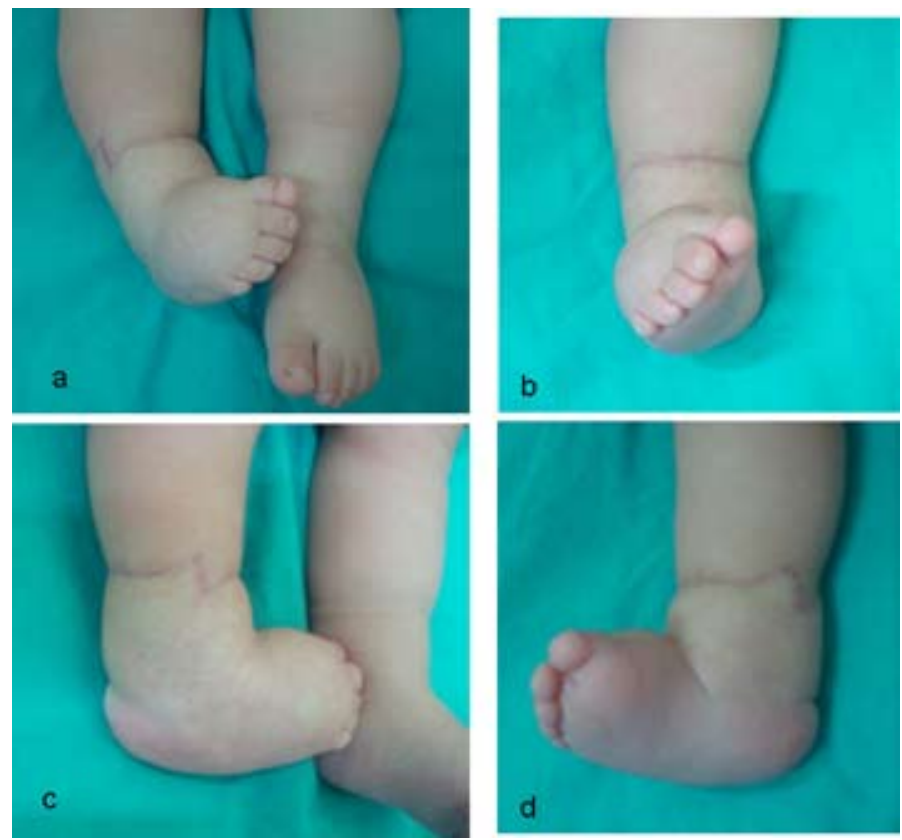

Şek. 4: Ameliyat sonrası altıncı ayda sağ bacağın; (a) oblik, (b) ön, (c) iç yan, (d) dış yan görünümleri.

minde minimal artış ve ekimoz görüldü. Ameliyat sonrası altıncı ay kontrolünde, bandın çıkarıldığı bölgede kontorün iyi olduğu gözlendi (Şek. 4).

\section{Tartışma}

Konstriktif ring sendromunun etiyolojisi tam bilinmemektedir. İntrauterin amniyotik bandların ekstremiteyi sarması nedeniyle oluştuğu tahmin edilmektedir. 
Hastamızda sol elde anomali ve 3-4 parmaklar arasındaki köprü şeklindeki bant yapısının varlığı intrauterin amniyotik bant tezini düşündürmektedir.

$\mathrm{Bu}$ hastalar değerlendirilirken ringin lokalizasyonu, derinliği, distalde lenfödem varlığı, distaldeki dolaşım sorunu varllğ 1 , ringin distalindeki uzvun fonksiyonelliği değerlendirilmeli, derin olan bantların eksizyonu gerekmektedir.

Konstrüktif bant sendromu vakalarının \% 80'inde başka el anomalileri de bulunur. Hastamızın sağ ayaktan başka sol el 3-4 parmaklarında ring benzeri yapılar mevcuttur.

Hastaların \% 40-50'sinde ise CL/P, kalp anomalileri, hemangiomalar ve meningomiyelosel de eşlik edebilir. Bu nedenle konstrüktif bant sendromu hastaların baş- ka pediatrik anomalisi olup olmadığ $\operatorname{araştırılmalı,~genel~}$ anestezisi buna göre planlanmalıdır.

Konstriktif ring sendromunda bandın eksizyonunda dolaşıma zarar vermemek için bandın çevresinin yarısından azının tek seferde serbestlenmesi önerilmektedir. Hastamızda bant eksizyonu çepeçevre tek seansta yapılmış, bu esnada kan dolaşımına zarar vermemek için mikroskop altında uygulanmıştır. Cerrahi sonrası dikkatli diseksiyon sayesinde hafif ödem artışı ve ekimoz dışında sorun gözlenmemiştir.

Hastanın cerrahi tedavisinde bant eksizyonuna ilave olarak kontür deformitesi nedeniyle pek çok vakada olduğu gibi Z-plastilere gerek duyulmuştur. Bunun için bacağın medyali ve lateraline z-plasti uygulanarak kontür düzeltilmiş, skar bandı oluşumu engellenmiştir.

\section{KAYNAKLAR}

Api, M., Görgen H., F1çıcıoğlu, Yorgancı, 1993. Amniotik Band Sendromu: Bir Olgu Sunumu, Perinatoloji Dergisi, 1, $231-235$.

Bourne, M., Klassen, R., 1987. Congenital Annular Constricting Bands: Review of the Literature and a Case Report. J. Ped. Orthop. 2, 218-221.

Coady, M.S., Moore, M.H., Wallis, K., 1998. Amniotic band syndrome: the association between rare facial clefts and limb ring constrictions. Plast. Reconstr. Surg. 101,640.

Di Meo, L., Mercer, D.H., 1987. Single-stage correction of constriction ring syndrome. Ann Plast. Surg. 19, $469-474$.

Filly, R.A., Golbus, M.S., 1991. The fetus with amniotic band syndrome. In Harrison MR, Golbus MS, Filly RA, eds: The Unborn Patient. Philadelphia, WB Saunders: 470.

Guy, D.F., Kent, R.M.D., 1994. Congenital Constriction Band Syndrome- A Seventy-Year Experience. J. Ped. Orthop.14, $242-248$. Miur, A.T., Chong, J.K., 1985. August. Congenital constriction band syndrome. Plast. Reconstr. Surg. $76,336$.

Muguti, G.I., 1990. The amniotic band syndrome: single-stage correction. Br. J. Plast. Surg. 43,706-708.

Ossipoff, V., Hall, B.D., 1977. Etiologic factors in the amniotic band syndrome: a study of twenty-four patients. Birth Defects. 13, 117.

Visuthikosol, V., Hompuem, T., 1988. Constriction band syndrome. Ann Plast. Surg. 21, 489-495.

Wiedrich, T.A., 1998. Congenital constriction band syndrome. Hand Clin.14, 29-38.

Walter, J.H., Goss, L.R., Lazzara, A.T., 1998. Amniotic band syndrome. J. Foot Ankle Surg. 37, 325. 